\title{
Entre el cenit de la apertura y la apatía del fraude. Prensa y política a inicio de los años cuarenta $(1940-1943)^{1}$
}

Ignacio A. López ${ }^{2}$

\section{Resumen:}

Este artículo tiene por objeto presentar un recorrido por las editoriales de los grandes diarios nacionales y provinciales, a fin de analizar los climas de opinión en los cuales estuvo envuelto el proceso político argentino de inicios de los años cuarenta. A través del análisis de tres precisas coyunturas o periodizaciones (febrero-agosto de 1940; marzo-junio de 1942; junio de 1943) intentaremos describir como la prensa acompañó la política del período y los principales acontecimientos políticos-electorales, y de esta manera, complejizar las imágenes del escenario político-institucional de inicio de los años cuarenta.En este sentido, el juego de escala que se propone el artículo intenta demostrar que, pese a la disonancia producto de improntas ideológicas y prismas geográficos diversos, en la lectura de los acontecimientos políticos, existió consonancia de diagnósticos sobre los principales problemas institucionales que rodearon esas coyunturas analizadas.

Palabras clave: Prensa - Elecciones - Roberto M. Ortiz - Ramón S. Castillo - Política

\section{Summary}

This article aims to present an itinerary of national and provincial newspapers editorials, in order to analyze the climate of opinion in which they were involved during the national political process in the early forties. Through the analysis of three precise critical times (February-August 1940, March-June 1942, June 1943), this paper attempts to describe how the press viewed the political-electoral events in the period, and in this sense, it presents a more complex analysis of the political scenario in the early forties. We assume that the press contributed to create a climate of opinion and it became a forum of discussion of the main problems in this constitutional period.Thus, the game of scale proposed in this article attempts to show that, despite ideological differences and geographical prisms, main political events were interpreted with consonance of diagnosis.

Keywords: Press - Elections - Roberto M. Ortiz - Ramón S. Castillo - Politics

\footnotetext{
${ }^{1}$ Trabajo recibido el 12/03/2016. Aceptado el 25/06/2016.

${ }^{2}$ Licenciado en Ciencia Política por la Universidad Católica Argentina. Magister en Historia por la Universidad Torcuato Di Tella. Becario doctoral del Consejo Nacional de Investigaciones Científicas y Técnicas. Contacto: ignaciolopez@gmail.com
} 


\section{Introducción}

La mañana del lunes 9 de marzo de 1940 despertó a los argentinos con titularesshockeantesde los principales diarios del país sobre la situación política inmediata: la provincia de Buenos Aires había sido intervenida y una movilización militar tomaba la casa de gobierno de La Plata. Una semana antes, la voz abaritonada del presidente de la República, Roberto M. Ortiz, resonó en los hogares a través de un mensaje radiofónico en cadena nacional. Allí el presidente decía estar más preocupado por el «perfeccionamiento de las instituciones democráticas» que por la «suerte de los partidos políticos»; de allí que ese domingo 8 de marzo, una semana después, y luego de un proceso electoral lleno de violencia, el gobierno nacional decidiese la intervención del primer estado argentinoy el desplazamiento del gobernador más poderoso: Manuel Fresco.

A lo largo de estas páginas buscaremos recrear a través de la prensa algunos trazos de la política argentina entre el año 1940 -fecha clave en la estrategia de democratización política propiciada por el presidente Ortiz- y junio de 1943, momento de la caída del gobierno del presidente Ramón S. Castillo por una insurrección militar. A través de algunos momentos políticos centrales de esos tres años, intentaremos primero, analizar las modulaciones editoriales de los grandes diarios sobre la política del período en escala federal y provincial, pero luego, discernir en clave de complejidad sobre los procesos políticos-electorales, los programas presidenciales del período y el clima de opinión del cual estuvieron rodeados.

Desde el punto de vista de la historia política, desde hace varias décadas en la producción académica se fue consolidando un consenso historiográfico alrededor de la figura del presidente Roberto M. Ortiz (1938-1942). Las conjeturas centrales de dicho consenso indicaron que el primer mandatario encaró un plan de democratización del sistema político a fines de la década conservadora, coartando el fraude electoral imperante y dando suficientes garantías de juego limpio para los partidos políticos opositores, en un contexto en la que la legitimidad del sistema democrático estuvo en debate y las prácticas electorales se vieron envueltas en mecanismos fraudulentos. ${ }^{3}$ También se ha señalado que como muestra del compromiso presidencial con las formas democráticas y su

\footnotetext{
${ }^{3}$ Melón Pirro, (1996); Macor y Piazzesi, (2005); De Privitellio, (2009).
} 
política anti-fraude era necesarioobservar las intervenciones federales (por su impacto territorial y político) ya que en ese preciso momento (febrero-marzo de 1940) y por la envergadura del acto, la voluntad presidencial se hizo visible. ${ }^{4}$

Sin embargo, los tiempos de la política argentina cambiaron rápidamente desde el pedido de licencia por razones de salud del primer mandatario durante julio de 1940. El programa conservador de viejos acuerdos y tolerancia al fraude se hizo evidente en manos del vicepresidente demócrata Ramón Castillo a cargo del Poder Ejecutivo, primero en forma provisional, luego en forma definitiva. La «brecha» entre un sistema político cada vez más excluyente y una sociedad en movimiento se hizo más profunda con el traspaso presidencial: la política de los acuerdos demostró su naturaleza ilegítima ante amplios sectores políticos y de la opinión pública. En ese escenario, la insurrección militar se activó como una salida exitosa dentro del repertorio de soluciones posibles para ese impasse institucional de los años treinta. ${ }^{5}$

Este artículo intentará abordar en tres precisas coyunturas (febrero-agosto de 1940,marzo-junio de 1942y junio de 1943) cómo la prensa, transformada en un coro diverso (con matices ideológicos y diversidad de miradas regionales), acompañó la política del período. De esta manera el artículo busca complejizar las imágenes del escenario políticoinstitucional de inicio de los años cuarenta.Si la primera coyuntura (febrero-agosto de 1940) remite al cenit de la apertura llevada a cabo por el presidente Ortiz, entre la intervención a la provincia de Buenos Aires y su renuncia por el escándalo de El Palomar; la segunda coyuntura (marzo-junio de 1942) reconstruye la cobertura mediática que rodeó su renuncia definitiva en junio de 1942. La tercera coyuntura explora el repertorio de imágenes y argumentosque la prensa gráfica presentó sobre el golpe militar de 1943.

Los vínculos entre periódicos, opinión pública y política han sido trabajados en diversos períodos históricos resaltando el rol de la prensa como «creadora de climas de opinión», por un lado, pero también como foro de discusión sobre temas política interna e internacional. ${ }^{6}$ Particularmente, el caso argentino ha sido fecundo en producción referida a la interacción entre prensa y política en tanto espacio de «republicaniza-

${ }^{4}$ Luna, (1979); Macor, (2001); De Privitellio, (2001); Macor y Piazzesi, (2005) y (2007);

López, (2011).

${ }^{5}$ Portantiero, (1987); Torre, (2006); Devoto, (2014).

${ }^{6}$ Speier, (2001): 376-377; Schweizer, (2006): 32; Rosanvallon (2006): 36. 
ción» de acuerdos y debates; y también en cómo la prensa activó y reprodujo manifestaciones callejeras durante fines del siglo XIX y principios del XX en diversas coyunturas críticas. ${ }^{7}$

Una serie de estudios sobre líneas editoriales de periódicos durante los años treinta son referencias metodológicas para este artículo. Así, aportes como el de María Inés Tato sobre La Fronda, ${ }^{8}$ aproximaciones como las de Jorge Nállim para La Prensa ${ }^{9}$ y Ricardo Sidicaro para La Nación ${ }^{10}$ en el mismo período nos ofrecen herramientas para indagar en qué medida las líneas editoriales de los periódicos estuvieron sujetas a una dinámica ideológica compleja durante ese turbulento contexto nacional e internacional. Los estudios de Sylvia Saítta para el diario Criti$c a^{11}$ sobre los años veinte; de Claudio Panella y Sabrina Ajmechet sobre La Prensa ${ }^{12}$ durante el peronismo y trabajos como el de James CaneCarrasco sobre los medios gráficos, periodistas y su relación con el Estado a partir de la segunda mitad de los años treinta, ${ }^{13}$ también nos brindan enfoques renovados sobre los vínculos entre la prensa y el poder político.

El coro de periódicos de alcance nacional y provincial reconstruidos en este artículo pretende brindar una imagen compleja sobre los diagnósticos que estos diarios hicieron sobre la realidad política de aquellos años. Este múltiple repertorio de fuentes incluye a los grandes diarios a nivel nacional (La Nación, La Prensa, Crítica, El Mundo); a aquellos con filiaciones políticas más claras como Noticias Gráficas (radical), La Vanguardia (socialista), La Fronda (demócrata nacional); pero también a un variado núcleo de periódicos provinciales con alcance diverso como Córdoba (Córdoba), La Voz del Interior (Córdoba), ${ }^{14}$ El Argentino (La Plata), El Día (La Plata), ${ }^{15}$ El Diario(Paraná), ${ }^{16}$ La Voz de Entre Ríos

\footnotetext{
7 Para el caso argentino: Alonso, (1997) y (2015); también los trabajos de Rojkind, (2006) y (2011).

${ }^{8}$ Tato, (2001) y (2004).

${ }^{9}$ Nállim, (2009).

${ }^{10}$ Sidicaro, (1993); (1996).

${ }^{11}$ Saítta, (1992); (1998).

${ }^{12}$ Panella, (1999); Ajmechet, (2010).

${ }^{13}$ Cane Carrasco, (2007).

14 Periódico cordobés fundado por Silvestre Rafael Remonda y Juan Dionisio Naso en 1904.

${ }^{15}$ Periódico platense fundado por Manuel Laínez, Arturo Ugalde, Martín Biedma y Julio Bote en 1884 .

${ }^{16}$ Diario de Paraná fundado en 1914 por el radical Luis Etchevehere.
} 
(Paraná), El Litoral (Santa Fe), ${ }^{17}$ El Orden (Santa Fe), ${ }^{18}$ Tribuna (Rosario), ${ }^{19}$ Los Andes (Mendoza). ${ }^{20}$

En este sentido, el juego de escala que se propone el artículo está dado por el cruzamiento devoces de la prensa en dimensión nacional y provincial, intentando demostrar que, pese a la disonancia producto de improntas ideológicas y prismas geográficos diversos, en la lectura de los acontecimientospolíticos, existió consonancia de diagnósticos sobre los principales problemas institucionales que rodearon esas coyunturas analizadas.

\section{Orquestaciones mediáticas en la primavera aperturista (febrero-agosto de 1940)}

Si bien el presidente Roberto M. Ortiz había asumido durante febrero de 1938, como sucesor del presidente Agustín Justo (1932-1936) y heredero de los acuerdos políticos de la Concordancia, ${ }^{21}$ fue en la particular coyuntura de febrero y marzo de 1940 cuando su programa de institucionalización (y de intolerancia a las prácticas electorales violentas) adquirió modos más definidos y visibles para sus socios de gobierno y partidos de la oposición. Durante el bienio previo, Ortiz se balanceó entre una retórica de saneamiento electoral anquilosada en un discurso de «perfeccionamiento democrático» y una política moderada de preservación de apoyos políticos-partidarios locales que, en algunos distritos,se tradujo en prescindencia -esto es, no intervención- en aras de preservar los acuerdos previos.

Pero la situación política en febrero y marzo de 1940cambió radicalmente. El presidente comenzó a dar señales de mayor apertura en su política anti-fraude en diciembre de 1939 cuando estalló un serio conflicto institucional para la conformación del colegio electoral que debía con-

\footnotetext{
${ }^{17}$ Fue uno de los diarios más importantes de la provincia. Había sido fundado en 1918 por Salvador Caputto.

${ }^{18}$ Diario matutino santafesino fundado por Alfredo Estrada en 1927.

${ }^{19}$ Periódico vespertino de Rosario vinculado a los demócratas progresistas. Fue fundado en 1928 por Mario Antelo, Enzo Bordabehere y Vicente Pomponio.

${ }^{20}$ Periódico mendocino fundado por Adolfo Calle en 1883.

${ }^{21}$ La Concordancia fue un frente electoral de partidos forjado en 1931 durante la candidatura presidencial del general Agustín Justo. Incluía al Partido Demócrata Nacional, al antipersonalismo radical, al Partido Socialista Independiente y a otros socios provinciales menores. Cfr. Macor, (2001).
} 
sagrar gobernador en Catamarca. En febrero asestó el primer golpe con la intervención de la provincia de su vicepresidente, Ramón Castillo, y días después, dio un segundo shock con el envío de una comisión federal a Buenos Aires. El mapa político cambió en marzo. Cuatro eran los distritos controlados directamente por el presidente, uno de los cuales adquiría normalidad constitucional con la elección de una fórmula radical antipersonalista con el aval del presidente (Santiago del Estero); en otros cuatro distritos se consolidaba la hegemonía del radicalismo: Entre Ríos, Córdoba, Tucumán y ahora Jujuy. La UCR se impuso en siete distritos y recuperaba la mayoría de la Cámara de Diputados, luego de doce años. El oficialismo, en sus múltiples matices, y alineado con los deseos del presidente, se afincaba en los restantes ocho. ${ }^{22}$

Algunos meses después, cuando se dirigió a la Asamblea Legislativa, el presidente consideró haber subsanado con su gravitación ejecutiva las «desviaciones que importaban la desnaturalización del sistema representativo en el ejercicio del derecho del sufragio». ${ }^{23}$ Pero más importante aún, sintetizó su programa democrático en los siguientes términos:

«En este segundo período de gobierno he dado fin a la primera etapa del programa politico y administrativo que anuncié y me propuse cumplir inflexiblemente al asumir la Presidencia. El plan realizado en estos dos años ha sido enteramente constructivo y de normalización politica e institucional [...] La libertad y las garantías constitucionales son la condición previa para crear el clima y el medio que han de permitir la extirpación de los vicios políticos a que me he referido, impropios de un pueblo celoso de su dignidad y libre albedrío» ${ }^{24}$

El primer semestre de 1940representó un doble movimiento en el calendario «orticista»: por un lado, su programa democrático se hizo visible para la opinión pública y los principales partidos de la oposición, y el presidente recibió la adhesión, en mayor o menor medida, de los más importantes medios gráficos independientes, y de destacadas publicaciones partidarias vinculadas al radicalismo, al socialismo y a la democracia progresista; ${ }^{25}$ pero por otro, desde el punto de vista estrictamente

\footnotetext{
${ }^{22}$ Ministerio del Interior, (1946).

${ }^{23}$ Ortiz, (1940): 2.

${ }^{24}$ Ortiz, (1940): 6-8.

${ }^{25}$ Hechos e Ideas, 03/1940; La Vanguardia, 08/03/1940; Tribuna, 08/03/1940.
} 
político, marzo de 1940, significó la consolidación del poder político presidencial, que aunque sin mediaciones partidaria, logró un control directo de algunas provincias, y se garantizó el apoyo tutelar del Ejército, a través del ministro de Guerra, Carlos Márquez.

Cuando el presidente Ortiz decretó la intervención a la provincia de Buenos Aires el 7 de marzo de 1940, los principales diarios de orden nacional y provincial respaldaron su política de democratización. Luego del discurso radiofónico del sábado 2 de marzo, en donde el presidente recordó sus deseos de respetar la voluntad popular y presidir comicios limpios, La Prensa señaló que la promesa presidencial respondía a «un propósito de gobierno» y el pueblo le exigiría «cuentas de su cumplimiento desde ahora en adelante». El diario, en línea a su ideario de liberalismo político, entendía que ese «ideal supremo» que el presidente Ortiz había expresado todavía no se había cumplido totalmente debido a algunas «transgresiones constitucionales», pero así como se demostraba dispuesto a «reaccionar en el orden político», podía y debía «rehabilitarse también en el orden institucional». ${ }^{26}$ Días después, otra editorial avaló la intervención federal a Buenos Aires -aún con la reserva de no haber sido sancionada por el Congreso Nacional- y consideró que ese hecho representaba una «liberación» para la provincia y el resto del país, así como también una «merecida sanción». ${ }^{27}$

La Nación, por otro lado, coincidía en que era «imprescindible» que desapareciera «la mentira de los comicios» que perturba el fundamento de la vida republicanay estimaba que la voluntad del presidente merecía «elogios». Como señaló Sidicaro, republicanismo y elecciones limpias fueron valores constantes en la línea editorial del periódico durante esta etapa, y apelar a la Constitución, ${ }^{28}$ se transformó en uno de los recursos favoritos: según el diario, el gobierno federal era el encargado de reprimir «desviaciones del régimen republicano»en las provincias, avalando la estrategia intervencionista. ${ }^{29}$ Así también, las editoriales del diario durante los días sucesivos, expresaron el deseo de que se inaugurara una «nueva etapa» en el país en la que no prevaleciera la «moral del comité»; ya que solo una «renovación de métodos y hombres» podría

\footnotetext{
${ }^{26}$ La Prensa (en adelante $L P$ ), 4/03/1940.

${ }^{27}$ LP, 8/03/1940.

28 Sidicaro, (1996).

${ }^{29}$ La Nación (en adelante $L N$ ), 1/03/1940.
} 
devolver la esperanza de una política «digna» de «nuestra riqueza y nuestra cultura». ${ }^{30}$

Crítica consideró la intervención a Buenos Aires como un hecho histórico. El periódico, cercano al oficialismo, no negaba su entusiasmo por la política de Ortiz. Celebraba la instauración de la democracia «después de diez años» y aplaudía la actitud presidencial que contaba con el apoyo de «todas las clases sociales». ${ }^{31}$ Señalaba expresiones de «júbilo popular» en diversas localidades bonaerenses ante la dimisión de Fresco, como así también declaraciones laudatorias al primer mandatario de la plana mayor del radicalismo: Marcelo T. de Alvear, Eduardo Laurencena, Santiago del Castillo, Vicente Gallo, Aldo Cantoni, entre otros. ${ }^{32}$

El Mundo, en tono más crítico, consideraba que los deseos del presidente Ortiz no eran ignorados por nadie y que la libertad electoral era una «frase» y no un «derecho», y tampoco un «hecho». El presidente («aquel ciudadano que habló al país con encomiable franqueza») le correspondía dar el ejemplo, ya que el gobierno federal debía «hacer mucho en beneficio de la verdad republicana en todo el territorio argentino». ${ }^{33}$ Y luego de la intervención, el diario aplaudió la intervención que devolvía al pueblo la «soberanía constitucional», «menoscabada» y «amputada» por el afán de conservar el poder. ${ }^{34}$

A nivel provincial, la adhesión a la política del presidente también era evidente en algunos medios gráficos. El Litoral señalaba que los acontecimientos de Buenos Aires adquirían un sentido más elevado, pese a ser crítico con la medida intervencionista: ese decreto expresaban el fin de la «reacción totalitaria», y la extinción de la «violencia» como sistema. ${ }^{35} \mathrm{El} \mathrm{Orden,} \mathrm{por} \mathrm{otro} \mathrm{lado,} \mathrm{consideró} \mathrm{ante} \mathrm{los} \mathrm{mismos} \mathrm{sucesos}$ que la adhesión del pueblo a los conceptos del presidente había sido «unánime», y pocas veces existió una «identificación tan firme entre los propósitos de un gobernante y la opinión pública de la Nación». ${ }^{36}$

Los periódicos bonaerenses El Argentino y El Día expresaban dos posturas diferentes ante tamaño acontecimiento político. El primero, desde el escepticismo, saludaba al interventor Amadeo recordándole sus ex-

\footnotetext{
${ }^{30} L N, 4 / 03 / 1940$.

${ }^{31}$ Critica, 7/03/1940.

${ }^{32}$ Critica, 8/03/1940.

${ }^{33}$ El Mundo (en adelante EM), 3/03/1940.

${ }^{34}$ EM, 8/03/1940.

${ }^{35}$ El Litoral (en adelante $\left.E L\right), 7 / 03 / 1940$.

${ }^{36}$ El Orden (en adelante, EO), 5/03/1940.
} 
presiones sobre Roque Sáenz Peña en Vidas Argentinas (1940) ${ }^{37}$ sobre los riesgos de presidentes que por «colocarse por arriba y por afuera de los partidos» buscaban hacer un gobierno democrático-con claras ironías del editorialista hacia la figura de Ortiz- ${ }^{38} \mathrm{El} \mathrm{Día,} \mathrm{por} \mathrm{el} \mathrm{contrario,}$ anunciaba en sintonía con la política presidencial y ante el escándalo electoral de febrero, que la esperanza en esa hora se orientaba a otros resortes (no a los del «libre juego de las instituciones provinciales») sino al de la «intervención»; ya que por ese medio se esperaba «restablecimiento de la verdad de nuestra democracia representativa». ${ }^{39}$ En su editorial del 8 de marzo, el diario consideró que pocas veces una intervención federal encontraba «un ambiente más favorable» $\mathrm{y}$ «tan sólidos motivos para su envío». ${ }^{40}$

Desde Córdoba, La Voz del Interior veía en el panorama político del país «un estado de transición efectiva» hacia prácticas más honestas y correctas, aunqueaún se estaba «muy lejos» de una marcha «recta y definitivamente» hacia la normalidad institucional, «desnaturalizada y envilecida» desde hacía diez años. La editorial del 3 de marzo, también reseñaba los episodios de violencia acaecidos en los procesos electorales de Salta y Jujuy, aunque expresaba sus esperanzas en la «mano redentora» del primer magistrado. ${ }^{41}$ El 7 de marzo, el periódico celebraba el «decreto histórico» ya que Ortiz había logrado una tarea fundamental: «colocarse y obligar a que se coloquen todos los gobiernos dentro de la órbita de la legalidad», ya que sin ésta existía principio de «orden, de paz, de armonía, de labor, de respeto mutuo»y consideraba la intervención como un «hito que marcaba el final de una época siniestra en la vida política argentina». ${ }^{42}$

Noticias Gráficas, por otro lado, luego de considerar que el discurso del sábado 2 de marzo de Ortiz «interpretó el anhelo de la Nación», ${ }^{43}$ señalaba su «esperanza» ante la «palabra cumplida» y consideraba que la misión federal a Buenos Aires era el «paso más importante adoptado en el bienio que acaba de cumplir el presidente Ortiz». Hacía muchos lus-

\footnotetext{
${ }^{37}$ Amadeo, (1940).

${ }^{38}$ El Argentino (en adelante EA), 11/03/1940, «Con el interventor ad portas».

${ }^{39} \mathrm{El} \mathrm{Día} \mathrm{(en} \mathrm{adelante,} \mathrm{ED),} \mathrm{28/03/1940.}$

${ }^{40} E D, 8 / 03 / 1940$.

${ }^{41}$ La Voz del Interior (en adelante $L V$ ), 3/03/1940.

${ }^{42} \mathrm{LV}, 8 / 03 / 1940$.

${ }^{43}$ Noticias Gráficas (en adelante $N G$ ), 3/03/1940.
} 
tros que el país no contaba con un gobernante que «supiese hablar y pensar como un estadista». ${ }^{44}$

Meses después, el presidente Ortiz debió solicitar licencia por el agravamiento de su estado de salud debido al cuadro crónico de diabetes que sufría. Un alejamiento que se creía temporario, terminó siendo permanente. Rápidamente, una serie de senadores oficialistas iniciaron un proceso de investigación sobre una compra irregular de tierras en El Palomar que tenía por objeto llevar a juicio político al ministro de Guerra, general Carlos Márquez, clave en la estrategia de acercamiento de Ortiz con el Ejército, y dar por elevación un golpe a la política de democratización del titular del Ejecutivo que estaba en suspenso por su licencia. ${ }^{45} \mathrm{Si}$ bien el escándalo terminó con una serie de diputados y civiles procesados y luego encarcelados, el juicio político a Márquez fue desestimado. Los resultados políticos fueron claros: durante septiembre de 1940 se produjo una reconfiguración del gabinete nacional que afianzó en la provisionalidad al vicepresidente Ramón Castillo y desplazó de las carteras claves a los más férreos orticistas.

En el cenit del conflicto, el presidente Ortiz presentó su renuncia ante la Asamblea Legislativa en un acto lleno de dramatismo. Si bien ésta fue desestimada por casi la totalidad de los legisladores, significó un importante respaldo institucional de todo el arco político -principalmente opositor-, pero además traslucía una importante adhesión a su figura en la opinión pública que se venía consolidando desde marzo. Si la política de apertura del presidente gozaba de un respaldo inusitado en la prensa gráfica y en los principales partidos opositores, en agosto de 1940, ese apoyo al presidente se hizo visible sin dobleces en la sociedad civil.

El 22 de agosto el presidente señaló en su texto de renuncia que el Senado de la Nación lo había «implicado» en su pronunciamiento y que su investidura resultaba «salpicada» en el negociado promovido por unos «ciudadanos inescrupulosos». Protestaba también por la intención de vincularlo como «cabeza de proceso» y veía Ortiz allí una maniobra política que buscaba romper el equilibro que debía existir «entre los dos poderes». Pero también adquirió tonos dramáticos. El presidente, en un gesto lleno de teatralidad, consideraba como «ineludible deber de conciencia» devolver el poder que le había conferido el pueblo, pues decía preferir «ser un ciudadano con dignidad que un presidente tildado de no ha-

\footnotetext{
${ }^{44} N G, 8 / 03 / 1940$.

${ }^{45}$ Sobre el escándalo de El Palomar, cfr. Bayer, (1976).
} 
ber cumplido con las más delicadas obligaciones de su cargo». En esa «hora amarga» de su vida, apelaba a la «conciencia honrada de sus conciudadanos», esperando posiblemente un contundente rechazo de la Asamblea.

Sin embargo, la misiva también fue importante en tanto nos otorga pistas del lugar en la historia que el propio presidente construía de sí mismo. Durante sus tres años de gobierno, decía haber trabajado por el «progreso material y cultural, por la paz y seguridad interior y exterior, por la normalidad institucional y por el bienestar de todos sus habitantes». Esa fidelidad a los ideales políticos, lo hizo respetar siempre la Constitución, pese a que ello le había suscitado «complicaciones políticas desagradables»; hasta tuvo que «adoptar decisiones trascendentales para el futuro de la República». Y en tono sintético señaló:

«En mi gobierno ha retornado el país a su tradicional vida democrática. Todos sus habitantes -sin distinción de partidos, ideologías o clases- gozan actualmente de las libertades políticas y derechos individuales que acuerda la Constitución. (...) Considero que la paz y la normalidad institucional y la política de juego limpio son las condiciones previas para realizar obra de gobierno constructiva y perdurable». ${ }^{46}$

Un acto masivo en el Luna Park fue organizado por la Confederación General del Trabajo (CGT) como muestra cabal del apoyo de los sectores obreros y sindicalistas al presidente y a su agenda institucional. En la noche del 23 de agosto, reunidos en el estadio, hablaron los líderes José Domenech, Francisco Pérez Leirós y Ángel Borlenghi expresando solidaridad con el enfermo renunciante, y una vez terminado al acto, una columna de manifestantes se dirigió a la residencia de la calle Suipacha en muestras de apoyo. ${ }^{47}$

La manifestación de respaldo no se agotó en ese acto masivo, obrero y político, donde convergieron socialistas, radicales y comunistas. Una mirada atenta a los telegramas y cartas de adhesión que llegaron al Congreso Nacional durante la sesión de Asamblea permite advertir una sociedad civil movilizada y que adhería a su presidente. Más de doscientos treinta telegramas arreciaron al recinto y fueron enviados por centros de

\footnotetext{
${ }^{46}$ Carta de Roberto M. Ortiz a la H. Asamblea Legislativa, Buenos Aires, 22/08/1940, en $L N, 23 / 08 / 1940$.

${ }^{47} L N, 24 / 08 / 1940$.
} 
colectividades (como los de refugiados españoles), comités contra el racismo y uniones sionistas; agrupaciones obreras y gremiales (ferroviarios, tranvías, ómnibus, empleados de comercio, textiles, construcción, entre otros); agrupaciones políticas como distintas filiales en todo el país, no solo de la UCR, sino también del Partido Comunista, Partido Socialista Obrero, y centros cívicos; diversas filiales de Acción Argentina; centro de Estudiantes de diversas carreras de las universidades de Buenos Aires, Nacional de La Plata y Nacional de Tucumán, y una pléyade de agrupaciones de estudiantes secundarios; varias cooperativas agrícolas y asociaciones empresarias; bibliotecas populares y clubes barriales de distintas ciudades del Interior; un importante número de agrupaciones de Mujeres y asociaciones educacionales; o simplemente una multiplicidad de telegramas de «ciudadanos sin ubicación ideológica pero demócratas de verdad». ${ }^{48}$

El reclamo por la «no aceptación» de la renuncia fue un grito al unísono desde todos los rincones del país. Los telegramas llegaron desde las grandes ciudades como Buenos Aires, La Plata, Córdoba, Rosario, Mendoza, Paraná, Bahía Blanca, Tucumán; de distintos grandes centros suburbanos bonaerenses como Avellaneda, Lanús y Quilmes; pero también desde un centenar de ciudades del interior, como Punta Alta, Olavarría, Carhué, Coronel Granada, Mercedes, Santos Lugares, Blaquier, San Justo, Arrecife, General La Madrid, San Martín, Chacabuco, Chivilcoy, Carmen de Patagones, en la provincia de Buenos Aires; de localidades como La Carlota, San Francisco, Río Cuarto, Marcos Juárez y Oliva, en la provincia de Córdoba; de Villa Mugueta, San Cristóbal, Barrancas, San Jorge, Moisés Ville o Helvecia, en el distrito de Santa Fe; de Palmira, San Martín, San Rafael y Monte Comán, en Mendoza; de Basavilbaso, Domínguez, Villaguay, Villa Federal, en la provincia de Entre Ríos; o de los remotos territorios nacionales, como las localidades de Presidencia de La Plaza (Chaco), Posadas, Apóstoles y Eldorado (Misiones), Viedma, Río Colorado y Villa Regina (Río Negro), Comodoro Rivadavia (Chubut) y Trenel y Jacinto Araúz (La Pampa). ${ }^{49}$

Sin embargo, la renuncia era percibida de modo diferente por el diario conservador La Fronda. Si bien se reconocía la «honestidad y la

\footnotetext{
${ }^{48}$ Honorable Cámara de Senadores de la Nación (HCSN), Diario de sesiones, Sesión de Asamblea, 24/08/1940, p. 1187, Carta de José Amigo y otros al presidente de la Asamblea Legislativa, 24/08/1940.

49 HCSN, Apéndice, 24/08/1940, pp. 1185-1217.
} 
entereza en la actitud presidencial» no pasaba por alto la «ligereza imperdonable» del documento de renuncia que se transformaba en un acto de «agresión al Poder Legislativo». ${ }^{50} \mathrm{El}$ diario demócrata consideraba la dimisión como «inobjetable» desde lo moral, y estimaba que dicho acto podía traer «cambios y definiciones» en la política presidencial. ${ }^{51}$ Para $L a$ Nación, al contrario, la renuncia de un primer mandatario solo se justificaba si existían «causas» que permitiesen a la opinión pública el convencimiento en tal sentido. Por ello, estimaba que el presidente no había sido afectado por el informe del Senado y recordaba la conducta del Poder Ejecutivo en materia de «libertades políticas» $\mathrm{y}$ «derechos individuales»: la opinión pública del país, en su «inmensa mayoría», reconocía la influencia de Ortizcomo «decisiva» a favor del «resurgimiento de las instituciones democráticas». ${ }^{52}$

La renuncia fue desechada por la Asamblea Legislativa al día siguiente. El presidente consolidó su imagen de demócrata y el arco político -opositor- demostró con gestos institucionales su respaldo a la política de Ortiz. Sin embargo, el poder real capitalizado por el enfermo estaba en su fase terminal. Las versiones de historiadores y contemporáneos sobre una victoria en esa crisis son realmentediscutibles. ${ }^{53} \mathrm{El}$ episodio del escándalo de El Palomar y la posterior renuncia devino en un impasse que se transformó en permanente.La lenta agonía de Ortiz comenzó en ese agosto y no tendría recuperación. Un nuevo proyecto presidencial comenzó a consolidarse a partir de septiembre y los tiempos políticos adquirirían una nueva dinámica.

\section{Hacia el retorno del fraude y el fin del orticismo (marzo-junio de 1942)}

Desde fines de 1940 y principios de 1941, el poder del vicepresidente Castillo se afianzó considerablemente. A fines de ese año 1940, nuevas elecciones tuvieron lugar en Mendoza y Santa Fe, y quedó claro que la estrategia del vicepresidente era de prescindencia ante los actos electorales fraudulentos escudándose en una férrea concepción de la «au-

\footnotetext{
${ }^{50}$ La Fronda (en adelante $L F$ ), 23/08/1940, «Un punto obscuro».

${ }^{51} L F, 23 / 08 / 1940$, «La renuncia presidencial».

${ }^{52} L N, 23 / 08 / 1940$, «La renuncia presidencial».

${ }^{53}$ Schillizzi Moreno, (1976): 258.
} 
tonomía provincial». ${ }^{54} \mathrm{~A}$ lo largo del año 1941, nuevos procesos electorales tuvieron lugar en Catamarca, San Juan y Buenos Aires, donde se impusieron los gobernadores demócratas y se transformaron en distritos claves del armado nacional del vicepresidente para controlar la llave de la próxima elección presidencial.

Durante febrero de 1941, los senadores concordancistas activaron una nueva comisión investigadora con el objeto de investigar el «verdadero» estado de salud del presidente. ${ }^{55}$ Varios meses sin comunicados médicos despertaban, según los senadores,un panorama «inquietante». Pero lo verdaderamente problemático era la «intromisión» que el presidente seguía teniendo sobre los asuntos nacionales. Con motivo de las elecciones en Santa Fe y Mendoza, Ortiz lanzó un comunicado donde condenaba los procesos electorales, ratificaba sus deseos de «normalización institucional» $\mathrm{y}$ respeto al sistema representativo, y acusaba al vicepresidente Castillo de «desdoblamiento moral». ${ }^{56}$

La comisión investigadora del Senado produjo una serie de documentos, sin consecuencias legales,pero que tuvieron un efecto político nítido: los antecedentes reunidos ratificaban la imposibilidad de Ortiz de reasumir en el corto plazo la presidencia. El efecto probó ser duradero: el presidente desapareció del mapa político hasta su renuncia en junio de 1942, mientras que la posición del vicepresidente Castillo se consolidó, disputando con el arbitraje del ex presidente Agustín P. Justo, que aparecía en cada distrito como una voz autorizada para dirimir conflictos locales.

La repercusión de la labor del Senado y los debates posteriores en los medios gráficos y principales dirigentes fue inmediata y unánime en condenar el accionar del Senado. La Nación advertía que el balance de la investigación había dejado un «saldo perdedor para el cuerpo» y que la pesquisa se había transformado en un «desastre» siendo investigada la misma comisión y no la salud del presidente. ${ }^{57}$ La Prensa, consideraba que si de algo había servido el proceso del Senado era para documentar que no fueron «institucionales» los móviles que lo determinaron sino la «notoria imprudencia» para contrariar las manifestaciones «bien inspiradas de la opinión pública» de algunos senadores. La índole de los inte-

\footnotetext{
${ }^{54}$ De Privitellio, (2001); Macor y Piazzesi, (2005).

${ }^{55}$ Comisión de Homenaje, (1941).

${ }^{56}$ Ortiz, Roberto M., «Manifiesto», en Hechos e Ideas, No. 39, febrero de 1941.

${ }^{57} \mathrm{LN}, \mathrm{1} / 051941$, «El fracaso del Senado».
} 
rrogatorios demostraba que la mayoría política del Senado buscaba «crear el ambiente propicio para alcanzar las soluciones que se anhelaban» como estrictamente políticas. Sin embargo, el saldo positivo era el «triunfo de la opinión pública» y la «derrota» la encarnaban los procedimientos y actuaciones de los mismos senadores.$^{58}$ El Mundo consideraba el affaire como una gran «improvisación vidriosa» y que de prosperar el proyecto de ley de la comisión especial se rompería el «equilibrio maravilloso» del sistema de gobierno republicano, en un momento en que el país no daba «cabida lícita» a los absolutismos. ${ }^{59}$ Para Noticias Gráficas el país había perdido la necesaria confianza en el cuerpo, con mayoría conservadora «obsesa por razones políticas inmediatas y subalternas» que buscaba «trabar el retorno de Ortiz al gobierno». ${ }^{60}$

El período que recorre los meses de marzo y junio de 1942 representó la transición definitiva hacia una nueva fase de la política nacional. Las elecciones legislativas de marzo; el nuevo reordenamiento de fuerzas triunfadoras en esas elecciones; el fallecimiento del ex presidente Marcelo T. de Alvear; y la renuncia definitiva del presidente Ortiz (y su muerte), dieron paso a la etapa última de la república reformada y a la consolidación final del proyecto político del vicepresidente Castillo. ${ }^{61} \mathrm{La}$ gravitación cada vez mayor, aunque silenciosa, del vicepresidente sobre las fuerzas demócratas, y un nuevo juego de alianzas con el Ejército se hacían cada vez más visibles dentro de la estructura decisional del Poder Ejecutivo Nacional. Paralelamente, el fallecimiento en esta etapa de Alvear, primero, y Ortiz, luego, sumados a un ambiente generalizado de «anomia»y desinterés visible en esas elecciones legislativas, develaron que el nuevo punto de equilibro de allí en más sería dado por la puja de fuerzas entre el ahora presidente Castillo y el general Justo que buscaba una reelección hacia 1943.

Las elecciones de marzo de 1942 presentaron algunos rasgos distintivos, sintomáticos de los tiempos que corrían: no solo fue estridente la derrota radical en algunos distritos -en los que no medió la maquinaria del fraude- como Capital Federal; sino que además, como fue señalado por Luciano dePrivitellio fue notorio el «escaso entusiasmo», la «incertidumbre» y una «creciente anomia» que corroía el sistema político

\footnotetext{
${ }^{58}$ LP, 2/05/1941, «Final merecido».

${ }^{59} E M, 20 / 041941$, «Razón de ser de un descontento público».

${ }^{60} \mathrm{NG}, 2 / 05 / 1941$, «Sanción carente de fuerza moral».

${ }^{61}$ De Privitellio, (2012).
} 
argentino. ${ }^{62}$ Paralelamente, la abstención radical en distintos como Catamarca, La Rioja y San Luis, hizo que la Concordancia se presentase sin oposición en los comicios y lograse acumular bancas. Pero además, fue cada vez más exitoso el «exclusivismo» que intentaba imprimir Castillo en la coalición oficialista: los demócratas ganaban peso, mientras que los radicales antipersonalistas se desvanecían o se hacían cada vez más «conservadores».63

En las elecciones de marzo votaron más de 3.194.000 de inscriptos distribuidos en más de 14.000 mesas. El resultado de las elecciones otorgó un holgado triunfo a las fuerzas oficialistas. El primer domingo de ese mes, se renovaron 85 bancas de diputados nacionales que correspondían 60 a la mayoría y 25 a la minoría. En Capital Federal se impuso el Partido Socialista con doce diputados, y se desplazó a la UCR en segundo lugar. En Buenos Aires, Catamarca, Corrientes, Entre Ríos, Jujuy, La Rioja, Mendoza, Salta, San Juan, Santa Fe, Santiago del Estero y Tucumán triunfaron las fuerzas demócratas o concordancistas. El radicalismo triunfó solo en Córdoba, en una derrota general estrepitosa lejana al triunfo legislativo de dos años antes que le había permitido obtener la mayoría en la Cámara Baja. ${ }^{64}$

En el ministerio del Interior se recibieron denuncias electorales de Buenos Aires y Entre Ríos, en mayor medida, y algunas denuncias aisladas en distritos como Santa Fe, Santiago del Estero y San Juan, ${ }^{65}$ pero en general el dispositivo del fraude operó de manera más selectiva, dando apariencia de comicios correctos en la mayoría de los distritos, en muchos casos, facilitado ese escenario por la abstención de los radicales. ${ }^{66} \mathrm{La}$ Nación, destacaba en sus editoriales del 1 y 2 de marzo que había una aspiración unánime a que las elecciones fuesen correctas, o al menos, sugería que «dentro de la imperfección» recurrente, existiese «un progreso en relación a las más discutidas de los últimos años», cuestión que efectivamente sucedió. ${ }^{67}$ En general, la tranquilidad en el ambiente en esos comicios fue destacada por la prensa nacional. ${ }^{68}$

\footnotetext{
${ }^{62}$ De Privitellio, (2001): 122.

${ }^{63}$ Piñeiro, (2014).

${ }^{64}$ Cfr. Ministerio del Interior, (1946): 609 y ss.

${ }^{65}$ Telegramas (varios) sobre elecciones legislativas del 1 de marzo de 1942, en Archivo General de la Nación (AGN), Archivo Intermedio, Dirección Nacional Electoral, Caja 47. ${ }^{66}$ Persello, (2004): 193.

${ }^{67} L N, 1 / 03 / 1942$, «Los comicios de hoy».

${ }^{68} L N, 2 / 03 / 1942$, «Las elecciones» y $L P, 2 / 03 / 1942$.
} 
En Mendoza, por ejemplo, la prensa local destacó que pocas veces los mendocinos habían concurrido a elecciones en un ambiente de tal «serenidad». Sin embargo, también era notable la campaña «fría» y «desprovista de ese entusiasmo ciudadano» que contagiaba el ambiente y la cultura cívica. ${ }^{69}$ Las elecciones legislativas habían sido producto de una «reacción cívica de acatamiento a las normas democráticas». ${ }^{70}$ En Santa Fe, El Litoral destacaba la forma «tranquila» en que se habían desarrollado los comicios, aunque no faltaron las postales clásicas de impugnación: retiro de fiscales radicales, presión policial, denuncias demoprogresistas. ${ }^{71}$ En Córdoba -la única provincia en la que triunfó el radicalismo- la prensa local daba cuenta de la división de los demócratas como un «verdadero lastre», denunciando acefalía de autoridades partidarias y abstención en algunos distritos históricamente conservadores. ${ }^{72}$ En las elecciones generales, sin embargo, logró imponerse el oficialismo bajo el liderazgo efectivo de Amadeo Sabattini y obtuvo los cuatro diputados por la mayoría y once bancas de las que estaban en juego en el Senado provincial. ${ }^{73}$ En Entre Ríos, la prensa de Paraná, oficialista y opositora, juzgaba los comicios entre la corrección y la farsa, sin punto medio. ${ }^{74}$

Unos meses después llegó la tragedia. El presidente Ortiz presentó su renuncia indeclinable a fines de junio de 1942 cuando sus médicos personales desestimaron cualquier intervención quirúrgica para aliviar su ceguera y retomar las funciones. El estado clínico del paciente se había agravado y era ya irreversible.

El fallecimiento del presidente, tan solo dos semanas después de su renuncia, conmocionó a todo el ambiente político y provocó un incesante desfile en el Salón Blanco de la Casa Rosada donde sus restos fueron velados. ${ }^{75}$ Como señaló Andrés Bisso, se puso en marcha una verdadera «canonización» popular del recién extinto, propia de la idealización de una figura que unía determinados elementos positivos para amplios sectores del arco político y la opinión pública, claramente aliadófila ante el avance de la Segunda Guerra Mundial y la aceleración de

\footnotetext{
${ }^{69}$ Los Andes (en adelante $L A$ ), 1/03/1942, «Los comicios de hoy».

${ }^{70} L A, 4 / 03 / 1942$, «Las elecciones del domingo».

${ }^{71} E L, 1 / 03 / 1942$.

${ }^{72}$ Córdoba (Córdoba), 11/03/1942.

${ }^{73}$ LP, 18/03/1942; y Tcach, (2007).

${ }^{74}$ Cfr. El Diario y La Voz de Entre Rios, 3/03/1942.

${ }^{75} \mathrm{LN}, 16 / 07 / 1942$.
} 
los acontecimientos luego del ataque japonés a Pearl Harbor. ${ }^{76}$

Ante el fallecimiento del presidente, La Prensa advertía la existencia de un «profundo sentimiento popular americano». No solo confluían en su sepelio hondos sentimientos de los argentinos, sino también consideraciones de orden político continental. Ese «esclarecido ciudadano» por sus «actos de gobernante y conducta privada» se había ganado el aprecio del pueblo. Pero a estos elementos subjetivos, se habían unido las «virtudes cívicas» de Ortiz que trascendieron fronteras, por haberse esforzado el presidente en servir «con lealtad y eficacia los principios sustantivos del régimen político de América». ${ }^{77}$

El diario Crítica describía las columnas que marchaban a despedir al presidente como de «voces enronquecidas y confusas»que adquirían por momentos una «intensidad de dolor, de protesta de queja y de reproche que elevaban el tono estremeciendo de un extremo a otro la columna». La despedida del féretro había sido una «imponente demostración de duelo popular». Según la editorial del diario, pocas veces se había consagrado semejante multitud en un acto de esa naturaleza y ello era debido a que el presidente «había luchado por devolverle los derechos al pueblo», y éste había expresado allí su «adhesión a la libertad».78

El Mundo, también reconocía en el extinto mandatario «un demócrata apasionado» y un «gran presidente». Solo habían bastado «dos años escasos» para comprobar el «acierto» que el pueblo había puesto en elegirlo y en su capacidad para dirigir el país en horas difíciles. Pese a que se estaba «demasiado encima de su figura» como para apreciarla en todo su conjunto y para poder «ponderar aquellos valores que solo la perspectiva y el tiempo destacaban», ya emergía lo positivo de su personalidad con facilidad: «su patriotismo» que en su acción cobraba un sentido permanente y el «liberalismo» que fue la nota predominante en su «fisonomía moral». ${ }^{79}$

Desde Córdoba, $\mathrm{La} \mathrm{Vzz}$ del Interior relató los últimos momentos de vida del presidente. En una nota biográfica, estimó que con Ortiz se perdía la Nación «un valor real» y «el pueblo, una esperanza». El mandatario exhibía «condición superior de soldado efectivo de la democracia»,

\footnotetext{
${ }^{76}$ Bisso, (2001): 150 y ss. Sobre la política exterior argentina durante esos años, cfr. Corigliano, (2009); Tulchin, (1969) y Escudé y Cisneros, (1998).

${ }^{77} \mathrm{LP}, 17 / 07 / 1942$, «El sentimiento popular americano».

${ }^{78}$ Critica, 16/07/1942.

${ }^{79}$ EM, 16/07/1942.
} 
y esa muerte venía a realizar la «unidad argentina», al menos en el sentido de dolor que provocaba: la que acababa de extinguirse era una «vida clara» a través de toda la multiplicidad de sus «facetas humanas». Incluso para la editorial «hasta sus conos de sombra» tenían valor distinto, como cuando se apreciaba el «brillo de la estrella». Ortiz, por tanto, había servido para cumplir una etapa de «transición»que iba del «ensoberbecimiento de una revolución triunfante» y una «normalidad» hacia la que necesariamente había que encaminarse el país:

«Luego de un período ominoso, de negación absoluta de todo valor sustantivo, de allanamiento de la libertad y de sojuzgamiento de los preceptos jurídicos, cuando la Nación estaba marginando abismos y todos los caminos conducían a la abyección porque ni siguiera la revolución era ya posible, se operó como un milagro, la reacción «de arriba». Es decir, el retorno gubernativo al cauce jurídico». ${ }^{80}$

\section{Entre la sorpresa y la inevitabilidad: miradas de la prensa ante el golpe de junio y el fin del gobierno de Castillo (junio de 1943)}

El segundo semestre de 1942 terminó por afirmar la posición del presidente Castillo. El titular del Ejecutivo nacional desplegó una política de acercamiento con los sectores de la oficialidad nacionalista, de reequilibrio en espacios provinciales de las fuerzas demócratas y de férrea neutralidad en política exterior. ${ }^{81}$ Hacia inicios de 1943, el poder del presidente fue lo suficientemente sólido como para imponer la candidatura presidencial del salteño Robustiano Patrón Costas y echar por tierra los intentos de rebeldía de los conservadores bonaerenses, que a través del gobernador Rodolfo Moreno, exigían un programa de gobierno y una redefinición de la política exterior. ${ }^{82}$

Sin embargo, los aliados castrenses sobre los que se apoyó el presidente demostraron ser no tan leales como se suponía. Cuando se produjeron los acontecimientos militares que terminaron con el gobierno del presidente, ${ }^{83}$ los grandes diarios nacionales reaccionaron entre la sor-

\footnotetext{
${ }^{80} \mathrm{LV}, \mathrm{16} / 07 / 1942$.

${ }^{81}$ Potash, (1986); Schillizzi Moreno, (1973).

${ }^{82}$ Carta de Justo Rocha a Gilberto Suárez Lago (PDN), La Plata, 2 de febrero de 1943, en AGN, Fondo Agustín P. Justo, Caja 134, doc. 309.

${ }^{83}$ Potash, (1986); Devoto, (2014).
} 
presa y el diagnóstico de inevitabilidad. Una mirada atenta, permite advertir que si para los grandes diarios nacionales los hechos convocaban a un resguardo de la tradición constitucional en esa precisa coyuntura, tambiénesos episodios de insurrección cerraban un ciclo en la política argentina que parecía como de fin inexorable.

La Nación, más prudente, recién dio por caído al gobierno el 5 de junio y recordaba en su editorial de ese día que el general victorioso del movimiento, Arturo Rawson, prometió desde el balcón de la Casa Rosada «respetar la Constitución». Era menester, en esa hora, «salvar las instituciones del Estado y propender a la grandeza moral y material de la Nación». ${ }^{84}$ La Prensa, con igual prudencia, anunció el triunfo del golpe el día después. En esas horas difíciles, recordaba el valor de la Constitución por ser ese el «único recurso seguro» para orientarse en «días de tormenta». El objetivo de las nuevas autoridades debía ser el de «poner en funcionamiento regular esos resortes institucionales» que establecía nuestra Ley fundamental. ${ }^{85}$

Otros periódicos como Crítica, anunciaban tempranamente que «un movimiento militar había triunfado» el mismo 4 de junio. Si bien reconocía la «total sorpresa por el estadillo», el periódico buscó interpretar esa insurrección como un «movimiento de esencia democrática y orientado a restablecer las garantías constitucionales» y señalaba que una muchedumbre había dado «vivas» a la democracia al paso de las tropas del general Rawson. ${ }^{86}$ En los días sucesivos, el diario enfatizó la «absoluta tranquilidad» que fue primando en todo el país y esperaba que el gobierno provisional tuviese «un mayor entendimiento con EE.UU.». En su editorial del 7 de junio, pedía al pueblo «tener fe» ya que se «estaba haciendo historia» en el medio de la bruma dramática de los acontecimientos. ${ }^{87}$

El Mundo consideraba que ese golpe no iba contra la Casa de Gobierno para «apuntalar» una política diferente en el exterior, sino que se orientaba al «orden interno» para restaurar con el «poderío de las armas» los derechos electorales reprimidos. Para el diario esa era una «revolución de fundamentos democráticos dentro de la restauración de la legalidad». Hacía tiempo, según el editorialista, se venía naufragando en

\footnotetext{
${ }^{84} L N, 5 / 06 / 1943$, «El cambio de gobierno».

${ }^{85}$ LP , 5/06/1943, «Cómo orientarse».

${ }^{86}$ Critica, 4/06/1943.

${ }^{87}$ Crítica, 5/06/1943 y 7/06/1943.
} 
un «mar confuso» sin poder reconocer la «tradicional estructura moral y política de la Nación» por lo que se necesitaba en esa hora una democracia que funcionara «biológicamente bien»: a través de la «franqueza de actos, verdad de los hechos y limpieza de procedimientos». ${ }^{88}$

Desde Córdoba, La Voz del Interior señalaba que el gobierno de Castillo había caído por su propio peso (de «masa muerta») como «fruto podrido». La proclama revolucionaria de los militares insurrectos era «clara, vibrante, rotunda (...) y promisoria». Para el periódico cordobés, ese movimiento significabauna reacción contra la «sistemática entronización del fraude, la venalidad, el peculado y la corrupción» que había impreso el último presidente conservador: el país se sentía «libre» de un gobierno que había instaurado la «venalidad como sistema», había «pisoteado al derecho», «enlodado la justicia»y «pervertido» al ciudadano común. ${ }^{89}$

En este sentido, la construcción de una «legitimidad» del golpe es notable en muchos periódicos provinciales. Desde la provincia de San Luis, según reconstruyen Navarrete y Martínez, la prensa local no daba cuenta de crisis política alguna en los días previos a la insurrección militar. Los tópicos centrales (la guerra mundial, obras públicas, actividades económicas a desarrollar en la Provincia, y el proceso de modernizacióninstitucional, entre otros) no reflejaban ninguna crisis latente. Sin embargo, el diario La Opinión rápidamente buscará legitimar al nuevo gobernador militar una vez producido el colapso. ${ }^{90}$

El Día, en la capital bonaerense, recordaba con pesar los tiempos de la revolución de 1930. Luego de trece años, estimaba que no se habían cumplido con los cometidos de dicho levantamiento que de la mano de Uriburu habían buscado «restablecer un equilibrio político y administrativo». En ese paréntesis de trece añoshabían subsistido»modalidades caracterizas por el fraude y la corrupción», por lo que la nueva insurrección sería una oportunidad para volver al cauce de la «legalidad» y a una «estructuración de formas» que permitiesen alcanzar el progreso «económico y espiritual sobre el estricto régimen de las leyes». ${ }^{91}$

Pero fue el diario socialista La Vanguardia el que sintetizaba mejor que cualquier otro el sentido político que tenía esa insurrección sobre

\footnotetext{
${ }^{88} E M, 5 / 06 / 1943$.

${ }^{89} L V, 5 / 06 / 1943$, «Ha caído el gobierno y la Nación quiere salvarse».

${ }^{90}$ Navarrete y Martínez, (2011): 12-13.

${ }^{91} E D, 5 / 06 / 1943$, «Bajo el signo de la revolución».
} 
el gobierno depuesto, en un clima muy lejano al que periódico percibió en «primavera» de los meses iniciales de 1940 con la apertura propiciada por Ortiz. En su editorial del día 4 de junio en el momento en que los acontecimientos se estaban produciendo, el diario consideraba que el hecho dominante del momento argentino era la «inmoralidad de la vida oficial», no referida a «trampas y tramoyas políticas» sino en sentido más restringido, al «desorden de conductas, a las irregularidades notorias de la vida administrativa, a la atmósfera de negociados grandes y chicos que circundan a la Casa Rosada y sus adyacencias». Comparaba la situación de «inmoralidad» con el lejano 1890, por la «mala política» y la «mala administración», ya que el fraude era la «expresión totalitaria del vicio oficial». ${ }^{92} \mathrm{Al}$ día siguiente, cuando un nuevo presidente de facto ocupaba la Casa Rosada, el diario brindó una imagen del gobierno caído que no tardaría en expandirse, y que cerraba el ciclo abierto por la política de democratización de Ortiz, poniendo esperanzas en un gobierno militarlleno de incertidumbres:

«Ayer cayó indefendido el gobierno indefendible. El ministro de la Guerra del señor Castillo barrió con el gobierno que vivía al margen de la Constitución. Desde ayer la fuerza reemplaza en el poder al fraude integral (...)Que la inspiración civil de nuestra historia, el mandato de las instituciones constitucionales, de los compromisos internacionalistas y el imperativo de respetar la voluntad del pueblo, inspiren inicialmente al gobierno provisional». ${ }^{93}$

\section{A manera de conclusión}

Las miradas de la prensa sobre los principales acontecimientos políticos y electorales entre 1940 y 1943 permiten advertir con claridad el escenario complejo de la política argentina, tensionado constantemente en esos años por la polarización ideológica y el conflicto mundial, por un lado, y por los avatares de la política doméstica, por el otro, que osciló entre la apertura electoral propiciada por el presidente Ortiz y el exclusivismo demócrata alentado por el presidente Castillo.

Un recorrido por las editoriales de los grandes diarios nacionales y provinciales, en un juego de escala, nos permitieron en estas páginas

\footnotetext{
${ }^{92}$ La Vanguardia, 4/06/1943.

${ }^{93}$ La Vanguardia, 5/06/1943.
} 
analizar los climas de opinión en los cuales estuvo envuelto el proceso político argentino de inicios de los años cuarenta y también señalar en qué medida la prensa colaboró en crear esos climas y convertirse en un foro de discusión de los principales problemasdel régimen constitucional imperante.

En tres precisas coyunturas (febrero-agosto 1940, marzo-junio de 1942, junio de 1943) las voces de un repertorio de diarios con diferente alcance geográfico y disímil aproximación ideológica confluyeron en dotar de densidad a algunos procesos políticos centrales durante inicios de los años cuarenta. Pero a su vez, las distintas trayectorias de los medios analizados, así como los puntos diversos del territorio nacional del cual escrutaron la realidad nacional, demuestran su rol complejo como plataformas de discusión sobre los grandes problemas de legitimidad de la década.

Si para 1940 los principales medios gráficos coincidieron en celebrar y aplaudir la política de democratización conducida «desde arriba» por el presidente Ortiz, su muerte en 1942 culminó con las esperanzas y significó la derrota de un posible cambio de régimen. Hacia 1943, los grandes diarios se balancearon entre la sorpresa y la inevitabilidad de los sucesos de junio. Para muchos periódicos ese invierno significó el fin de un ciclo, y la caída de Castillo abriría las compuertas del sistema político a un proceso lleno de incertidumbres.

\section{Bibliografía}

AJMECHET, Sabrina, (2010), El principio del fin o de cómo el peronismo cambió a La Prensa. Un estudio del diario y su relación con la politica, Tesis de Maestría en Historia, IDAES, Universidad Nacional de General San Martín.

ALONSO, Paula, (1997), «En la primavera de la historia. El discurso político del roquismo de la década del ochenta a través de su prensa». Boletin del Instituto de Historia Argentina y Americana «Dr. Emilio Ravignani», Tercera serie, 15: 35-70.

ALONSO, Paula, (2015), «La historia de la política y la historia de la prensa: Los desafíos de un enlace». En PINEDA SOTO,Adriana (coord.), Recorridos de la prensa moderna a la prensa actual. México: Universidad Autónoma de Querétaro.

BAYER, Osvaldo, (1976), «Palomar: negociado que conmovió a un ré- 
gimen». En: Todo es Historia, 2. Buenos Aires: 69-93.

BISSO, Andrés, (2005), Acción Argentina. Un antifascismo nacional en tiempos de Guerra Mundial. Buenos Aires: Prometeo.

CANE CARRASCO, James, (2007), «Trabajadores de la pluma. Periodistas, propietarios y Estado en la transformación de la prensa argentina, 1935-1945». En DA ORDEN, María Liliana y MELÓN PIRRO, Julio César (comps.), Prensa y peronismo. Discursos, prácticas, empresas, 1943-1958. Rosario: Prohistoria.

CORIGLIANO, Francisco, (2009), «La Argentina frente a la Segunda Guerra Mundial. La neutralidad acosada (1939-1945)». En: Todo es Historia, 506: 54-76.

DE PRIVITELLIO, Luciano, (2001), «La política bajo el signo de la crisis». En CATTARUZZA, Alejandro (Dir.), Crisis económica, avance del Estado e incertidumbre política (1930-1943). Buenos Aires: Sudamericana.

DE PRIVITELLIO, Luciano, (2009), «El imperio de la voluntad popular: el fraude y el estudio de las elecciones en la primera mitad del siglo XX». La Fundación Cultural. Ágora, Espacio de Historia y Ciencias Sociales, 38, Santiago del Estero, Fundación Cultural Santiago del Estero.

DE PRIVITELLIO, Luciano (2012), «La vida política». En CATTARUZZA, Alejandro (Coord.), Argentina. Mirando hacia adentro. Madrid: Fundación Mapfre-Santillana Ediciones.

DEVOTO, Fernando (2014), «Para una reflexión en torno al golpe del 4 de junio de 1943». En: Estudios Sociales. Revista universitaria semestral, 46: 171-186.

ESCUDÉ, Carlos y CISNEROS, Andrés (1998), Historia de las Relaciones Exteriores argentinas. Buenos Aires: GEL.

LÓPEZ, Ignacio (2011), «El desmantelamiento del fraude patriótico: las intervenciones federales durante los años de Roberto M. Ortiz (1938-1940)». Anuario del Centro de Estudios Históricos Carlos Segreti, Córdoba, 11: 107-127.

LUNA, Félix (1979), Ortiz: Reportaje a la Argentina opulenta. Buenos Aires: Sudamericana.

MACOR, Darío (2001), «Partidos, coaliciones y sistema de poder». En CATTARUZZA, Alejandro (Dir.), Crisis económica, avance del Estado e incertidumbre política (1930-1943). Buenos Aires: Editorial 
Sudamericana, tomo VII.

MACOR, Darío y PIAZZESI, Susana (2005), «La cuestión de la legitimidad en la construcción del poder en la Argentina de los años treinta». Cuadernos Sur Historia, Bahía Blanca, 34: 9-34.

MACOR, Darío y PIAZZESI, Susana (2007), «Organizaciones partidarias, elecciones y elites políticas. Santa Fe (Argentina), 1930-1943». Boletin Americanista, Barcelona, LVII, 57: 107-132.

MELÓN PIRRO, Julio César (1996), «Legislación y práctica electoral en la década de 1930. La 'Ley trampa' y 'el fraude patriótico'». En MELÓN PIRRO, Julio César y PASTORIZA, Elisa (ed.) Los caminos de la democracia. Alternativas y Prácticas Politicas 19001943. Buenos Aires: Biblos.

NÁLLIM, Jorge (2009), «AnUnbrokenLoyalty in Turbulent Times: La Prensa and Liberalism in Argentina, 1930-1946». En: Estudios Interdisciplinarios de América Latina y el Caribe, 20, 2: 35-62.

NAVARRETE, Marcela H., y MARTÍNEZ, Cintia D. (2011), «Discurso y poder: el golpe de Estado de 1943 en la prensa puntana». En: Question. Revista especializada en Periodismo y Comunicación. La Plata, 1, 32: 1-15.

PANELlA, Claudio (1999), La prensa y el Peronismo. Critica, Conflicto, Expropiación. Buenos Aires: Ediciones de Periodismo y Comunicación.

PERSELLO, Ana Virginia (2004), El partido radical. Gobierno y oposición, 1916-1943. Buenos Aires: Siglo XXI.

PIÑEIRO, Elena (2014), Creyentes, herejes y arribistas. El radicalismo en la encrucijada, 1924-1943. Rosario: Prohistoria.

PORTANTIERO, Juan Carlos (1987), «Transformación social y crisis de la política», Suplemento «La Argentina de los años 30. Momentos y figuras de la crisis». En: La Ciudad Futura. Revista de Cultura Socialista, Buenos Aires: 14-15.

POTASH, Robert (1986), El ejército y la politica en la Argentina: 19281945. De Yrigoyen a Perón. Buenos Aires: Hyspanoamérica.

ROJKIND, Inés (2006), «Prensa, manifestaciones y oposición política. La protesta contra la unificación de la deuda en julio de 1901». En: Estudios Sociales. Revista universitaria sem., Santa Fe, No 31, 1:137-162.

ROJKIND, Inés (2012), «El gobierno de la calle. Diarios, movilizaciones y política en el Buenos Aires del novecientos». Secuencia. Re- 
vista de historia y ciencias sociales, No84: 99-123.

ROSANVALLON, Pierre (2006), «TheStudy of Politics in History». En: MOYN, Samuel (Ed.), Democracy. Past and Future. New York: Columbia University Press.

SAÍTTA, Sylvia (1992), «Crítica en los años '30. Entre la conspiración y el exilio». En: Entrepasados, Buenos Aires, 2, 2,25-39.

SAÍTTA, Sylvia (1998), Regueros de tinta. El diario Crítica en la década de 1920. Buenos Aires: Sudamericana.

SCHILLIZZI MORENO, Horacio (1973), Argentina contemporánea. Fraude y entrega, 1930-1943. Buenos Aires: Plus Ultra.

SCHWEIZER, Karl (2006), «Newspapers, Politics and Public Opinion in the Later Hanoverian Era». En: ParliamentaryHistory, $\mathrm{N}^{\circ} 25,1$ : $32-48$.

SIDICARO, Ricardo (1993), La politica mirada desde arriba. Las ideas del diario La Nación. Buenos Aires: Sudamericana.

SIDICARO, Ricardo (1996), «El diario La Nación ante la democracia y su primer ciclo de crisis». En MELÓN PIRRO, Julio César y PASTORIZA, Elisa (Ed.), Los caminos de la democracia. Alternativas y prácticas politicas, 1900-1943. Buenos Aires, Biblios: 23-37.

SPEIER, Hans (2001), «Historical Development of Public Opinion». En: Anàlisi, No 26: 209-221

TATO, María Inés (2001), «Crónica de un desencanto: una mirada conservadora de la democratización política, 1911-1930». En: Estudios Sociales. Revista universitaria sem., Santa Fe, No 20, 1:143-163.

TATO, María Inés (2004), Viento de fronda: liberalismo, conservadurismo $y$ democracia en la Argentina, 1911-1932. Buenos Aires: Siglo XXI.

TCACH, César (2007), «Un radicalismo exitoso en la Argentina de los treinta. El caso del sabattinismo cordobés». En: Boletín Americanista, Barcelona, LVII, 57: 133-156.

TORRE, Juan Carlos (2006), «La crisis argentina de principios de los años cuarenta y sus alternativas. El peronismo y los otros». En TORRE, Juan Carlos. La Vieja Guardia Sindical y Perón. Buenos Aires: Eduntref.

TULCHIN, Joseph (1969), «The Argentine Proposal for Non-Belligerency, April 1940». En: Journal of Inter-American Studies, $\mathrm{N}^{\circ} 11$, 4: 571-604. 